\title{
DA METÁFORA COMO MEDIAÇÃO PEDAGÓGICA
}

\author{
Thiago Rodrigues*
}

\begin{abstract}
Resumo
O presente estudo visa ressaltar o papel da imagem como elemento mediador no processo de aprendizagem. É um pressuposto necessário a esta reflexão: o desequilíbrio existente entre a supervalorização dos aspectos lógico-racionais em detrimento de uma educação fundada na intuição e na espontaneidade, para isso é preciso, portanto, resgatar essa dimensão negligenciada; para tanto, uma postura problematizadora (antidogmatizante) se impõe; o que nos lança numa pedagogia centrada na (inter)subjetividade que resgata a dimensão patológica implicada no processo educacional.
\end{abstract}

Palavras-chave: Páthos-filosófico. Lógos-racional. Antidogmatismo. Imagem. Subjetividade.

\begin{abstract}
This study aims to highlight the role of the image as a mediating element in the learning process. Presupposition is required for this reflection: the imbalance between the overvaluation of logical-rational aspects at the expense of an education founded on intuition and spontaneity, it is therefore necessary to rescue this neglected dimension; for both, a based problem approach (no-dogmatism) is required; which places us in a centered pedagogy (between) subjectivities, which rescues the pathological dimension involved in the educational process.
\end{abstract}

Keywords: Philosophical-pathos. Rational-logos. No-dogmatism. Picture. Subjectivity.

* Mestre em Filosofia pela Universidade Federal de São Paulo (UNIFESP). Professor na Universidade Federal de São Paulo (UNIFESP). Coordenador dos cursos de Especialização (Lato Sensu) em História do Pensamento Político e Social; e Filosofia Contemporânea pela mesma instituição.E-mail: coord.contemporanea@unifai.edu.br 
Destarte alguns pressupostos a esta reflexão devem ser explicitados. Sabemos que a tradição do pensamento ocidental historicamente privilegiou os aspectos lógico-racionais da existência humana em detrimento de sua esfera instintiva. É chegada a hora então - e este alerta já não configura novidade $^{1}$ - de se resgatar a dimensão passional da existência implicada no processo pedagógico. Nesse sentido, a distinção proposta nas reflexões nietzscheanas, entre o páthos-filosófico e o lógos-racional, se insurge como pressuposto necessário ao que se segue. Vejamos.

Diz Nietzsche:

Todo nosso mundo moderno está preso na rede da civilização alexandrina e conhece como ideal o homem teórico, equipado com os máximos poderes de conhecimento, trabalhando a serviço da ciência, cujo protótipo e ancestral é Sócrates. Todos os nossos meios de educação têm em vista, primordialmente, esse ideal. ${ }^{2}$

Um ideal de racionalidade, o ideal do lógos normativo do discurso racional. Assim, quando o autor diz que a filosofia principia sua derrocada com o pensamento intelectualista clássico representado pela figura de Sócrates, ${ }^{3}$ o que está em jogo é exatamente a supervalorização dos aspectos racionais, ou melhor, a supervalorização do discurso normativo do ideal de racionalidade, que deve a qualquer custo suprimir a intuição e a sensibilidade, em outros termos, a subjetividade, do processo formativo. ${ }^{4}$ E quando falamos em discurso normativo do lógos-racional, temos em mente o caráter prescritivo que essa formulação recebe ao longo da história. Ou seja, deve-se a todo custo buscar o ideal asséptico de cientificidade, hoje, mais especificamente, decorrente dos resquícios de uma visão positivista do conhecimento.

\footnotetext{
${ }^{1}$ Alerta presente, entre outras, na proposta da Escola Nova (SAVIANI, D. 2009, p. 8-9).

2 NIETZSCHE, 1978, p. 17-18, §18, grifo nosso).

3 Ibidem, p. 12 §13 "Enquanto em todos os homens produtivos o instinto é precisamente a força criadora-afirmativa e a consciência se porta como crítica e dissuasiva, em Sócrates é o instinto que se torna crítico e a consciência, criadora".

4 Sabemos que a passagem da intuição e sensibilidade à subjetividade se dá de forma mais complexa do que aqui exposto, no entanto, e ao que se pretende, não nos parece imprescindível esse aprofundamento.
} 
Posto isto, já podemos afirmar que nossas primeiras prerrogativas dizem respeito ao primado da subjetividade e a uma pedagogia que valorize a espontaneidade e a sensibilidade no processo de ensino-aprendizagem. ${ }^{5}$ Daí o lugar privilegiado reservado à imagem e às abordagens imagéticas decorrentes das artes.

Nesse sentido, outro pressuposto importante que surge, e que deve ser explicitado, diz respeito à relação entre discente e docente. Novamente aqui nossa posição não parece acrescentar nada ao que já foi dito, pois, contra a "educação bancária", é preciso romper com a hierarquização no processo de aprendizagem. Em outras palavras, é preciso exercer uma pedagogia que não negligencie o aluno e suas vivências. Entretanto, sabemos do fosso que separa esta afirmação teórica da prática docente. Justifica-se, desse modo, a reiteração desses pressupostos.

Uma pedagogia centrada na subjetividade do aluno e no encontro entre docente e discente, parece exigir um educador "problematizador" em detrimento da tradição "bancária" que ainda parece imperar. ${ }^{6}$ Em outros termos, é preciso romper com o modelo pedagógico que orienta a prática corrente, por exemplo: se o acento na relação de aprendizagem está na (inter)subjetividade do aluno, que sentido faz impor um currículo dado que anteceda o encontro entre docente e discente? Assim, (e aqui ainda estamos no registro freiriano) é preciso partir da realidade que circunda o aluno e dos problemas que o afligem, e não de uma "grade curricular" pronta e pré-definida.

A partir destes pressupostos, então, entendemos o educador como aquele provocador que visa problematizar a realidade do aluno antes de impor um referencial teórico apartado da realidade social e (por que não?) existencial do educando.

Problematizador porque parte de certo ceticismo metodológico. Antidogmatismo talvez fosse o termo mais apropriado para aquilo que chamamos aqui de ceticismo metodológico. Por antidogmatismo entendemos aquela postura prática inerente ao ceticismo pirrônico transposto por Oswaldo Pereira Porchat como uma "filosofia enquanto visão comum do mundo", em outros termos, é preciso partir de uma definição de filosofia como

5 Cabe frisar que entendemos a relação entre ensino e aprendizagem como correlatos e, mais que isso, como um processo dinâmico e não hierarquizado, em outras palavras, discentedocente compreendem dois lados de um mesmo processo.

6 Evidente está, que aqui, reverberam as ideias de Paulo Freire. (Cf. FREIRE, 1996). 
atividade, diz Porchat, filosofia é investigação criadora. ${ }^{7}$ É nesse sentido que tomamos também como uma prerrogativa o entendimento da sala de aula como o lugar do encontro de uma comunidade investigativa ${ }^{8}$ e é nesse registro também que surge àquilo que chamamos acima de "uma quebra na hierarquia entre docente e discente". Se a filosofia, tal como também defende Cerleti, ${ }^{9}$ é um certo modo de olhar, é uma atividade perscrutadora, uma atividade filosófica portanto, então devemos entender que uma aula de filosofia( "filosófica") ${ }^{10}$ é uma atividade que visa construir significado e nunca oferecer respostas prontas. ${ }^{11}$

Não entraremos aqui na querela entre o lugar do filosofar e da história da filosofia para o ensino de filosofia, pois, claro está, que qualquer posicionamento que se reduza a um dos polos da questão se configurará como um reducionismo ingênuo. Assim, o problema do lugar do ensino da filosofia, no que tange a esta discussão, é um falso problema, pois não se trata de abandonar o rigor metodológico exigido no registro historiográfico, mas antes, garantir a especificidade do ensino de filosofia, sobretudo, na Educação Básica. ${ }^{12}$

Entretanto, é preciso dizer que a concepção do ensino de filosofia pressupõe uma filosofia que a fundamenta e orienta. Vejamos. É natural que um professor de filosofia, que entenda por filosofia a análise das suas construções lógicas, adote uma prática docente divergente daquela empregada por um professor de uma orientação que a entenda como resultado de um longo processo histórico-econômico. Ora, se assim é, então só podemos pensar no ensino de filosofia se antes respondermos a pergunta: o que é isto - a filosofia? Assim, se a cada concepção de filosofia corresponde uma resposta, talvez a única resposta possível seja aquela sugerida por Porchat,

7 PORCHAT, 1983, p. 19.

8 Para uma melhor compreensão deste conceito de reverberações lipmanianas, recomendamos o excelente livro de LORIERI,M, Filosofia: fundamentos e métodos. São Paulo: Cortez, 2002.

9 Cf. CERLETTI, 2008. p. 19-42.

${ }^{10}$ Ibidem, p. 31.

${ }^{11}$ Ainda no que tange a compreensão da filosofia como atividade perscrutadora, cabe remetermo-nos as instigantes reflexões de Mário Gonzáles Porta em seu livro A filosofia a partir de seus problemas. No qual o autor defende uma concepção de filosofia como uma forma de lançar "questões", formular problemas fundamentais.

${ }^{12}$ Neste ponto nossa reflexão se coaduna com aquela defendida por Rodrigo (2009, p. 45ss). 
qual seja, a de que não é possível oferecer uma resposta definitiva a esta pergunta. Então como estabelecer as diretrizes para o ensino de filosofia?

Parece-nos que a única alternativa é assumir que a verdade das filosofias não pode ser abarcada em sua totalidade e que, portanto, este não-lugar da filosofia é que deve pautar o ensino da mesma. Parece-nos, portanto, que o antidogmatismo acima citado é prerrogativa básica para adentrarmos no pensamento filosófico. Concepção esta que se coaduna com aquela imagem do professor "problematizador" apregoada por Freire à que aludimos anteriormente. O professor é, antes de tudo, aquele que, a partir das vivências do educando, lança problemas e provocações a ele. Incita-o a produzir respostas a partir de uma "investigação criadora". Se o ceticismo metodológico apregoa que não há lugar para a Verdade absoluta, então não nos parece um abuso adotar uma concepção dinâmica de verdade e, por consequência, de filosofia. Não nos parece absurdo assumir o conflito das filosofias como mais uma prerrogativa necessária. Assim, não compete ao professor ensinar verdades filosóficas, mas antes, buscar respostas na tradição filosófica aos problemas levantados pelos próprios discentes e atualizados para a realidade contemporânea.

Há um pressuposto fundamental ao modelo pedagógico tradicional que é o de que o professor detém a verdade, por isso professa. Se partimos de uma concepção dinâmica para a verdade, então não faz sentido um modelo no qual o professor transmita seu conhecimento ao aluno. Ora, se não falamos aqui em transmissão de conhecimentos, para não reduzir o processo à transmissão de informações, falamos do que então? Daí que a expressão que tomamos de empréstimo de Porchat ganhe relevo, precisamos conceber uma aula de filosofia como uma investigação criadora, como um processo coletivo que busque responder às perguntas também construídas coletivamente. Entretanto, isso implica numa série de alterações fundamentais na prática cotidiana do professor de filosofia. Tomemos como mote, neste ponto, as ideias de Nietzsche quando problematiza o problema da verdade. ${ }^{13}$

No célebre texto do autor Sobre a verdade e a mentira no sentido extra-moral, o filósofo tece severa crítica ao referencial filosófico tradicional no que tange a verdade, pois, segundo ele, a verdade surge como o necessário corolário de um pretenso convívio social pacífico. Assim, a gênese de nossa compreensão de verdade é a linguagem, que determina aquilo que

\footnotetext{
${ }^{13}$ Para uma leitura mais aprofundada. (Cf. MACHADO, 2002).
} 
entendemos como verdade ou mentira, deste modo a aversão à mentira que o ocidente erigiu como referência se deve ao fato das consequências negativas que o engano pode trazer a este modelo. Desse modo, a verdade deve garantir a estabilidade do modelo social vigente, e a linguagem funciona como seu instrumento.

Há aqui um contraponto entre o real e sua representação pela linguagem, assim o real é revestido e sempre reconstruído mediado pela linguagem.

O que é a verdade, portanto? Um batalhão móvel de metáforas, metonímias, antropomorfismos, enfim, uma soma de relações humanas, que foram enfatizadas poética e retoricamente, transpostas, enfeitadas, e que, após longo uso, parecem a um povo sólidas, canônicas e obrigatórias: as verdades são ilusões, das quais se esqueceu que o são, metáforas que se tornaram gastas e sem força sensível, moedas que perderam sua efígie e agora só entram em consideração como metal, não mais como moedas. ${ }^{14}$

Os cânones estão estabelecidos e a verdade é sempre a verdade de um certo ponto de vista, construído e localizado historicamente.

Aqui, embora o pequeno salto, nos remetemos, finalmente, à concepção sartriana de verdade enquanto processo e passamos à segunda parte da nossa breve reflexão: Qual o papel da imagem e, mais especificamente, da metáfora enquanto mediadora no processo de aprendizagem?

\section{II}

Povo miserável! É culpa minha se em vosso meio vaguei como uma cigana pelos campos e tenho de me esconder e disfarçar, como se eu fosse a pecadora e vós os meus juízes? Vede minha irmã, a Arte! Ela está como eu, caída entre bárbaros e não sabemos mais nos salvar. Aqui nos falta, é verdade, justa causa; mas os juizes diante dos quais encontraremos justiça têm também jurisdição sobre vós, e os dirão: Tendes antes uma civilização, e então ficareis sabendo vós também o que a filosofia quer e pode. (NIETZSCHE, A Filosofia Trágica na Época dos Gregos, §2).

${ }^{14}$ NIETZSCHE, 1978, p. 48, § 1. 
É notória a crítica que Sartre realiza à concepção tradicional de imagem. Para o autor, consciência imaginante e consciência perceptiva não se confundem, isso porque, no seu entendimento, é preciso compreender a consciência enquanto um ato, isso implica na recusa à toda e qualquer tentativa de se substancializá-la. Deste modo, um objeto não pode de modo algum estar $n a$ consciência, pois a imagem mental "é um certo modo que o objeto tem de aparecer à consciência". ${ }^{15}$ Em outras palavras, a imagem é um ato da consciência ao relacionar-se com o objeto.

O problema aqui levantado refere-se ao modo como a consciência opera ao constituir o objeto imaginário. O que é uma imagem mental? Qual a distinção entre imagem e percepção? E principalmente, o que é o imaginário?

Para Sartre toda tradição filosófica, no que tange ao problema da imagem mental, tratou de substancializar a consciência, transformando-a numa espécie de receptáculo povoado por pequenos simulacros. Nesse sentido, a imagem nada mais é do que uma cópia menor $d a$ coisa $n a$ consciência, um conteúdo da e na consciência, o que implica necessariamente em uma concepção substancialista. ${ }^{16}$

Para melhor compreendermos as críticas de Sartre à esta tradição, é preciso explicitar seus pressupostos fenomenológicos, pois, como bem lembram Bento Prado e Moutinho na apresentação à edição brasileira de $O$ imaginário de Sartre, este é um livro escrito contra Husserl, e completa Sartre, "mas apenas na medida em que um discípulo pode escrever contra o seu mestre". ${ }^{17}$

Em A transcendência do ego, Sartre destaca que Husserl não havia radicalizado suficientemente um de seus conceitos basilares, que é o conceito de intencionalidade, o que inclusiv, levou alguns comentadores a falarem em "escola francesa de fenomenologia". Este comentário parece pertinente porque, para Sartre, a consciência existe como puro ato, como relação com o mundo. Ou na imagem utilizada pelo filósofo, a consciência é como um

\footnotetext{
${ }^{15}$ SARTRE, 1992, p. 19.

${ }^{16}$ Ora, se não se trata de um objeto que deve ser introjetado na consciência, então, não deveríamos conceber outro modo para estruturar a educação? Em outras palavras, não se trata mais de transmitir um conteúdo pronto, mas antes de desenvolver a capacidade de problematizar e desconstruir modelos condicionados pela tradição, se a filosofia é atividade criadora, então precisamos construir um modelo que contemple esse necessário dinamismo.

${ }^{17}$ SARTRE, 1992, p. 7.
} 
vento, uma explosão em direção a algo, mas que nunca é em-si-mesma, nunca se realiza. A consciência é pura relação com o mundo.

Cabe então apresentarmos o que o filósofo entende por percepção e o que ele entende por imagem para melhor compreendermos o nosso problema.

Em primeiro lugar, em ambos os casos, trata-se de um ato intencional da consciência, o que significa que eles nunca se dão simultaneamente. Se percebo não imagino, se imagino não posso perceber.

Diz Sartre:

o objeto da percepção é constituído por uma multiplicidade infinita de determinações e de relações possíveis. Ao contrário, a imagem mais determinada não possui senão um número finito de determinações, precisamente aquelas de que temos consciência. ${ }^{18}$

Em outras palavras, podemos dizer que o autor reserva à consciência imaginante um papel criador (ativo) e a consciência perceptiva, ao contrário, um papel de apreensão (passivo). É por isso que Sartre diz que não há nada na imagem que já não esteja posto no ato de imaginar. Enquanto que na percepção sempre há algo que eu posso apreender que ainda não estava posto.

Assim, a consciência imaginante tem um papel ativo, pois ela é uma "espontaneidade que produz e conserva o objeto como imagem". ${ }^{19} \mathrm{O}$ que faz com que a consciência perceptiva apareça como passiva ${ }^{20}$ diante do objeto percebido.

Ora, estes pressupostos são fundamentais para compreendermos o que Sartre entende por imaginário, pois, para o autor este tipo de consciência tem uma função irrealizante. Isso significa que o imaginário é o lugar no qual a consciência cria o irreal enquanto negação do real. Mas isso não implicaria na aceitação da consciência imaginante como o lugar de uma certa forma de alienação? Sim e não, pois, se por um lado ela pode ser apropriada como uma forma de fuga do real pela má-fé, por outro lado ela só pode constituirse tendo como pano de fundo o real constituído, "a nadificação [...] sempre implica por seu constituir-se no mundo". ${ }^{21}$ Portanto, diz Sartre:

${ }^{18}$ SARTRE, 1992, p. 30.

${ }^{19}$ SARTRE, 1992, p. 28.

${ }^{20}$ Evidentemente o termo "passiva" aqui surge em sentido fraco, pois, não nos esqueçamos, a consciência é, sempre, intencional.

${ }^{21}$ Ibidem, p. 241. Que significa um recuo em relação ao mundo, mas que, no entanto, só se constitui inserida no mundo. 
É a situação-no-mundo, apreendida como realidade concreta e individual da consciência, que serve de motivação para a constituição de um objeto irreal qualquer, e a natureza desse objeto irreal é circunscrita por essa motivação. ${ }^{22}$

Assim, entender a consciência imaginante enquanto ato significa resgatar seu papel de desveladora de instâncias inauditas do próprio real, é resgatar seu pressuposto fundamental que é a noção fenomenológica de intencionalidade tal como concebe a interpretação francesa do existencialismo sartriano.

Portanto, mais do que uma facilitadora no processo de apreensão de conteúdos conceituais apregoados pelo discurso do lógos normativo, a metáfora deve ser entendida como instância criadora da realidade humana mesma. Em outras palavras, o irreal apresentado (construído) pela criação ficcional mais do que figurar (representar) o real é responsável por sua transfiguração. ${ }^{23} \mathrm{O}$ irreal é produzido pelo real e ao mesmo tempo é produtor da realidade humana. Assim, a pergunta fundamental que subexiste a esta reflexão é: como é possível mensurar o papel do imaginário na constituição daquilo que chamamos de real? Ou antes, mas o que é o real afinal? Surge, deste modo, a prerrogativa hermenêutica fundamental ao que nos propomos, qual seja, aquela acerca do conflito das interpretações.

Diante do acima exposto, entendemos que a arte deva desempenhar um papel central dentro deste processo, evidente que isso implica em uma reformulação do modelo educacional herdado de nossa tradição tecnicista. ${ }^{24}$

${ }^{22}$ Ibidem, p. 241.

${ }^{23}$ Sobre o conceito de refiguração de Ricoeur: "A refiguração narrativa define-se como o "poder que a narrativa possui de reorganizar a nossa experiência temporal", descobrindo ao mesmo tempo "as profundezas dessa experiência" e transformando a orientação que se imprime à vida a partir desse momento".

${ }^{24}$ Assim define Saviani (2009, p. 11) a pedagogia tecnicista: "A partir do pressuposto da neutralidade científica e inspirada nos princípios de racionalidade, eficiência e produtividade, a pedagogia tecnicista advogou a reordenação do processo educativo de maneira a torná-lo objetivo e operacional. De modo semelhante ao que ocorreu no trabalho fabril, pretendeu-se a objetivação do trabalho pedagógico. Buscou-se, então, com base em justificativas teóricas derivadas da corrente filosófico-psicológica do behaviorismo, planejar a educação de modo a dotá-la de uma organização racional capaz de minimizar as interferências subjetivas que pudessem pôr em risco sua eficiência. Se na pedagogia tradicional a iniciativa cabia ao professor e se na pedagogia nova a iniciativa deslocouse para o aluno, na pedagogia tecnicista o elemento principal passou a ser a organização 


\section{III}

E, por fim, em que nesse mundo importa aos nossos jovens a história da filosofia? Será que eles devem, pela confusão das opiniões, ser desencorajados de terem opiniões? Será que devem ser ensinados a participar do coro do júbilo: como chegamos tão esplendidamente longe? Será que, porventura, devem aprender a odiar ou desprezar a filosofia? Quase se poderia pensar este último, quando se sabe como os estudantes têm de se martirizar por causa de suas provas de filosofia, para imprimir as idéias mais malucas e mais espinhosas do espirito humano, ao lado das mais grandiosas e mais dificeis de captar, em seu pobre cérebro. A única crítica de uma filosofia que é possivel e que, além disso, demonstra algo, ou seja, ensaiar se se pode viver segundo ela, nunca foi ensinada em universidades: mas sempre a crítica de palavras com palavras. Eagora pense-se em uma cabeça juvenil, sem muita experiência da vida, em que cinquenta críticas desses sistemas são guardados juntos e misturados - que aridez, que selvageria, que escárnio, quando se trata de uma educação para a filosofia! Mas, de fato, todos reconhecem que não se educa para ela, mas para uma prova de filosofia: cujo resultado, sabidamente e do hábito, é que quem sai dessa prova - ai, dessa provação! - confessa a si mesmo com um profundo suspiro: "Graças a Deus que não sou um filósofo, mas cristão e cidadão do meu Estado!" (NIETZSCHE, Schopenhauer como Educador, §8).

Chegamos então a nossa hipótese fundamental: o que significa buscar uma aprendizagem significativa? Se nossa hipótese estiver correta, a aprendizagem só é significativa quando criadora. Assim, contra uma pedagogia conformadora, deformadora, que condiciona ao invés de libertar, precisamos efetivamente abandonar o modelo tradicional e buscar mecanismos para potencializar uma educação que seja efetivamente libertadora.

A verdadeira compreensão exige a participação ativa daquele que aprende. Apenas conhecemos verdadeiramente alguma coisa quando participamos ativa-

racional dos meios, ocupando o professor e o aluno posição secundária. A organização do processo converteu-se na garantia da eficiência, compensando e corrigindo as deficiências do professor e maximizando os efeitos de sua intervenção". 
mente no processo de sua (re)construção, quando empregamos nossa liberdade para e na produção do conhecimento. Nesse sentido, a fala de Paulo Freire sintetiza perfeitamente nossa posição: "Ninguém liberta ninguém, e ninguém se liberta sozinho. A libertação se dá em comunhão, ou se se preferir, no encontro". ${ }^{25}$ Ora, se o processo de aprendizagem exige a participação ativa tanto do educador quanto do educando, então, se Sartre tiver razão quando diz que é através do recurso ao imaginário que o homem lança mão de sua liberdade, é através do apelo à imagem e ao imaginário que o processo de aprendizagem deve se pautar.

Lembremos rapidamente de algumas das ideias de Paulo Freire.

Sob a influência da escola filosófica do pragmatismo, a Pedagogia da Autonomia apresenta como um de seus pressupostos fundamentais a compreensão do processo pedagógico como prática ativa de ensino-aprendizagem. Acrescida do diálogo desenvolvido por Paulo Freire com o referencial da fenomenologia, sua proposta apregoa uma pedagogia contextualizada, o que implica na necessária politização do processo educacional. Isso significa, primeiramente, que a informação que não leva em conta o contexto em que está inserida, que não se relaciona cognitivamente com o uso cotidiano que dela decorre, não se efetiva como conhecimento adquirido. Assim, quando desarticulado da vivência concreta, o conhecimento se transforma numa anomalia que ao invés de libertar, aprisiona. Lembremo-nos ainda de Freire quando este diz que a leitura do mundo antecede a leitura da palavra mundo, ou seja, aquela relação entre o real e a representação do real pela linguagem proposta por Nietzsche citada anteriormente, segundo Freire, tem como substrato o real. Quando surge a representação o real já estava lá para condicioná-la. Daí que o discurso nunca é neutro, é preciso um exercício ativo para compreendermos aquilo que o condiciona.

Em Sartre, a imagem é instância ativa, lugar da criação e da liberdade, logo, lugar privilegiado para a instauração de um modelo de educação que não negligencie o páthos criador requerido nas reflexões nietzscheanas que nos serviram de mote inicial. Acreditamos então numa pedagogia patológica, isto é, num modelo de educação que não negligencie este pressuposto fundamental de que o ponto de partida deve ser sempre a subjetividade discente, seu modo de ser no mundo, sua situação histórica, ou se se preferir, sua realidade social.

${ }^{25}$ No original: "Ninguém liberta ninguém, ninguém se liberta sozinho: os homens se libertam em comunhão." (FREIRE, 1987, p. 29). 
Ora, se falamos aqui da metáfora enquanto mediação pedagógica então se justifica lançarmos mão da clássica imagem tecida por Kant na introdução à Crítica da Razão Pura, diz o filósofo: "A leve pomba, ao sulcar livremente o ar, cuja resistência sente, poderia crer que no vácuo melhor ainda conseguiria desferir o seu voo". ${ }^{26}$ A comparação aproxima as tentativas infrutíferas da razão pura em metafísica com os esforços da pomba para voar sem resistência do ar.

Existe toda uma tradição de autores que se debruçam sobre essa imagem, a pergunta que cabe então é: por quê? Seria pela falta de univocidade da linguagem metafórica? Ou seria pela requisição intrínseca à imagem de uma efetiva participação daquele que a lê? Se falamos da imagem como elemento de constituição da realidade humana e da criação como fundamento do processo pedagógico, então, perece-nos lícito ressaltar sua função mediadora dentro do processo pedagógico.

Por fim, posto o papel da imagem no processo de constituição realidade, tal como visamos ressaltar anteriormente, não configura abuso lançar mão da metáfora kantiana como forma de reconstruirmos nosso discurso (sempre precário e provisório). ${ }^{27}$ Assim, quando Kant se refere ao voo de uma pomba, imaginamos a pomba. O que vemos? É só a pomba voando? Quando vemos uma pomba é só o voo da pomba que vemos? Ou seria toda uma geometria dos corpos, uma biologia dos espaços vazios? Ou seria ainda a pomba encantada por elucubrações imaginárias que habitam nossa forma de compreender o mundo? "Fecho os olhos e vejo uma bandada de pássaros. A visão dura um segundo ou talvez menos; não sei quantos pássaros vi. Era definido ou indefinido o seu número?"28 Àqueles que conhecem Borges, como pensar no voo da pomba sem se remeter a esta passagem?

Voltamos ao nosso ponto, o que é o real (realidade) sem a mediação do imaginário? E se através do imaginário, tal como quer Sartre tenho que me colocar ativamente no processo de constituição da realidade humana e, ainda, se é apenas através da criação que a aprendizagem significativa se processa, então não se justificaria um modelo pedagógico centrado no recurso ao imaginário? Não se faz necessário buscar mecanismos que tornem este processo libertador?

A rigor, se acompanhamos esta reflexão até aqui, perceberemos que a me-

\footnotetext{
${ }^{26}$ KANT, 2001, B9, p. 67.

${ }^{27}$ As passagens a seguir se remetem as instigantes reflexões de Rubens Torres Rodrigues Filho em $A$ virtus dormitiva de Kant.

${ }^{28}$ BORGES, 1987, p. 15.
} 
táfora já não se configura como mediadora, mas antes como instância criadora. É sim, parte fundamental no processo pedagógico, no entanto, não se limita a mediar conteúdos conceituais, no limite ela é fruto da situação no mundo e, ao mesmo tempo, parte criadora da realidade humana. Portanto, é por intermédio do recurso ao imaginário e a imagem que o conhecimento autêntico se constitui.

\section{Referências}

ALMEIDA, D. D. M. de. Subjetividade e discurso da qualidade educacional: contra a difamação do docente. Revista do COGEIME, Piracicaba, v. 14, n. 26, p. 95-105, Jun. 2005.

BORGES, J. L. O fazedor. Tradução de Rolando Roque da Silva. 4. ed., São Paulo: Globo, 1987.

CERLETI, A. A. Ensinar filosofia: da pergunta filosófica à proposta metodológica. In: KOHAN, W. O. (Org.). Filosofia: caminhos para seu ensino. Rio de Janeiro: Lamparina, 2008.

DIAS, R. M. Cultura e educação no pensamento de Nietzsche. Impulso, Piracicaba, v. 12, n. 28, p. 33-40, Jul. 2001.

FREIRE, P. Pedagogia da autonomia: saberes necessários à prática educativa. São Paulo: Paz e terra, 1996. (Col. Leitura).

. Pedagogia do oprimido. 17. ed., Rio de Janeiro: Paz e Terra, 1987.

GENTIL, H. S. Para uma poética da modernidade: uma aproximação à arte do romance em Temps et Récit de Paul Ricoeur. São Paulo: Edições Loyola, 2004.

KANT. I. Crítica da razão pura. Tradução de Manuela Pinto dos Santos e Alexandre Fradique Morujão. Introdução e notas de Alexandre Fradique Morujão. 5. ed., Lisboa: Edição da Fundação Calouste Gulbenkian, 2001.

LORIERI, M. Filosofia: fundamentos e métodos. São Paulo: Cortez, 2002.

MACHADO, R. Nietzsche e a verdade. Rio de Janeiro: Rocco, 2002.

MOUTINHO, L. D. S. Sartre: existencialismo e liberdade. São Paulo: Moderna Editora, 1995. 
liense, 1995.

. Sartre: psicologia e fenomenologia. São Paulo: Editora Brasi-

NIETZSCHE, F. O nascimento da tragédia no espírito da música. Tradução e notas de Rubens Rodrigues Torres Filho. 2. ed., São Paulo: Abril Cultural, 1978. (Col. Os Pensadores).

. Schopenhauer como educador. In: . Considerações extemporâneas. Tradução e notas de Rubens Rodrigues Torres Filho. 2. ed., São Paulo: Abril Cultural, 1978. (Col. Os Pensadores).

. A gaia ciência. Tradução e notas de Paulo César de Souza. São Paulo: Companhia das Letras, 2001.

. Sobre a verdade e a mentira no sentido extra-moral. Tradução e notas de Rubens Rodrigues Torres Filho. 2. ed., São Paulo: Abril Cultural, 1978. (Col. Os Pensadores).

PAIVA, R. Subjetividade e imagem: a literatura como horizonte da Filosofia em Henri Bergson. São Paulo: Associação Editorial Humanitas; Fapesp, 2005. PORCHAT, O. P. O conflito das filosofias. In: . A filosofia e a visão comum do mundo. São Paulo: Brasiliense, 1983.

PORTA, M. A. G. A filosofia a partir de seus problemas. São Paulo: Edições Loyola, 2003.

RICOEUR, P. Tempo e narrativa. Tradução de Claudia Berliner. WMF Martins Fontes, 2011. v. 3. . Metáfora viva. São Paulo: Edições Loyola, 2005.

RODRIGO, L. M. Filosofia em sala de aula: teorias e práticas para o ensino médio. São Paulo: Escritores Associados, 2009. (Col. Formação de Professores). SAINT-SERNIN, B. Philosophie et fiction. Temps Modernes - n. 531-3, Oct./Dec., 1990.

SILVA, F. L. e. Ética e literatura em Sartre: ensaios introdutórios. São Paulo: Editora UNESP, 2004. 
SARTRE, J. P. Uma idéia fundamental da fenomenologia de Husserl: a intencionalidade. In: . Situações I. Tradução de Cristina Prado. Prefácio de Bento Prado Jr. São Paulo: Cosac Naif, 2005.

. Une idée fondamentale de la phénomenologie de Husserl: l'intentionalité. In: . La transcendance de l'ego. Paris: Vrin, 2003.

. A transcendência do ego. Seguido de consciência de si e conhecimento de si. Tradução e introdução de Pedro M. S. Alves. Lisboa: Edições Colibri, 1994.

. La transcendance de l'ego. Paris: Vrin, 2003.

. A imaginação. Tradução e notas de Vergílio Ferreira; Sel. José Américo Motta Pessanha. São Paulo: Abril Cultural, 1978. (Col. Os Pensadores).

. O imaginário. Tradução de Duda Machado. São Paulo: Ática, 1992.

SAVIANI, D. Escola e democracia. 41. ed. revista. Campinas: Autores Associados, 2009.

TORRES FILHO, R. R. Ensaios de filosofia ilustrada. São Paulo: Iluminuras, 2004.

Data de registro: $11 / 04 / 2014$

Data de aceite: $17 / 12 / 2014$ 